\section{International Scientific Journal Theoretical \& Applied Science}

\author{
p-ISSN: 2308-4944 (print) e-ISSN: 2409-0085 (online) \\ Year: $2016 \quad$ Issue: 12 Volume: 44
}

Published: 28.12.2016 http://T-Science.org

\section{Denis Chemezov}

Master of Engineering and Technology, Corresponding Member of International Academy of Theoretical and Applied Sciences, Lecturer of Vladimir Industrial College, Russian Federation chemezov-da@yandex.ru

Elena Kiseleva Master of Industrial Training, Vladimir Industrial College, Russian Federation

SECTION 25. Technologies of materials for the light and textile industry.

\title{
A STENCIL MANUFACTURE IN THE CONDITIONS OF JSC «ZAVOD «AVTOPRIBOR» (VLADIMIR, RUSSIA)
}

Abstract: The article is presented the sequence of the technological process of stencil manufacturing from the monofilament polyester fabric. Recommendations for quality control of the manufacture of stencil are given.

Key words: a stencil, a drying, a fabric.

Language: Russian

Citation: Chemezov D, Kiseleva E (2016) A STENCIL MANUFACTURE IN THE CONDITIONS OF JSC «ZAVOD «AVTOPRIBOR». ISJ Theoretical \& Applied Science, 12 (44): 79-83.

Soi: http://s-o-i.org/1.1/TAS-12-44-16 Doi: crossef http://dx.doi.org/10.15863/TAS.2016.12.44.16

\section{ТРАФАРЕТНОЕ ПРОИЗВОДСТВО В УСЛОВИЯХ ОАО «ЗАВОД «АВТОПРИБОР» (г. ВЛАДИМИР, РОССИЯ)}

Аннотация: В статье представлена последовательность технологического процесса изготовления трафарета из моноволоконной полиэфирной ткани. Даны рекомендации по контролю качества изготовления трафарета.

Ключевые слова: трафарет, сушка, ткань.

\section{Введение}

ОАО «Завод «Автоприбор» (г. Владимир, Россия) в настоящее время является одним из ведущих предприятий по производству автомобильных компонентов. Завод был основан в 1932 году и на протяжении 84-х лет обеспечивает выпуск электрооборудования и приборов для различных моделей автомобилей, автобусов, тракторов, комбайнов, мотоциклов и т. д. Система качества на предприятии по ИСО 9001, ИСО/ТУ 16949:2002 и ИСО 14001:2004 подтверждена сертификатами, выданными органом по сертификации «Дет Норске Веритас» (Норвегия).

На предприятии имеются следующие виды производств: сборочное, штамповое, сварочное, изготовление и сборка печатных плат, переработка пластмасс, литейно-механическое, автоматно-механическое, лакокрасочное и гальваническое. Трафаретная печать шкал приборной панели автомобиля выполняется в лакокрасочном производстве. Внедрены технологии изготовления трафаретов и последующей печати шкалы тахометров, логометров, манометров, спидометров и других комплектующих для сборки автомобилей (ПАО «АвтоВАЗ»). Для более качественной и точной трафаретной печати был приобретен новый автомат модели DEK.

В настоящей статье авторами предлагается к рассмотрению технологический процесс изготовления трафарета для печати шкалы приборов автомобиля.

\section{Материалы и методы исследования}

В качестве исходного материала трафарета применяется моноволоконная полиэфирная ткань (РЕT) [1]. Волокна ткани имеют следующие свойства: удельный вес - 1.38; предел прочности при растяжении в сухом состоянии - 45..75 даН/мм²; относительная влажность - $100 \%$; увеличение при разрыве во влажном состоянии $15 \ldots 30 \%$; увеличение при разрыве в сухом состоянии - $15 \ldots 30 \%$; влагопоглощение при температуре $20{ }^{\circ} \mathrm{C}$ и относительной влажности 65 $\%$ - $0.4 \%$; температура плавления - $240 \ldots 260{ }^{\circ} \mathrm{C}$; температура размягчения - 220..240 ${ }^{\circ} \mathrm{C}$; термостойкость в сухом состоянии - при температуре сушки до $150{ }^{\circ} \mathrm{C}$ постоянная устойчивость; свето- и атмосферостойкость - от 
хорошей до очень хорошей; устойчивость к истиранию - хорошая.

Натяжение ткани на трафаретную форму выполняется на пневматической зажимной системе SETAR 3 по схеме, представленной на рис. 1. Последовательность технологического процесса изготовления трафаретов и оборудование для нанесения фотоэмульсии [2] представлены на рис. 2 - 6 .

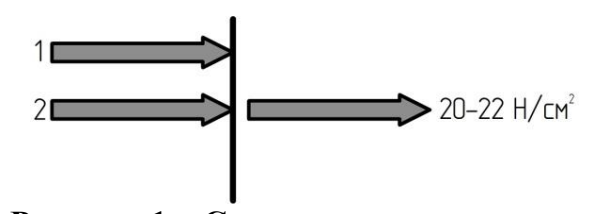

Рисунок 1 - Схема натяжения ткани.

На схеме условно обозначены:

1 - 120.34 ULTRA ORANGE [3] - яркооранжевая ткань, плотность - 120 нит/см, диаметр нити - 34 мкм, размер отверстия открытой части ячейки - 45 мкм, коэффициент открытой поверхности - $29 \%$, толщина ткани 63 мкм, теоретический объем краски $-18 \mathrm{~cm} / \mathrm{m}^{2}$, вес $-34 \Gamma / \mathrm{M}^{2}$.

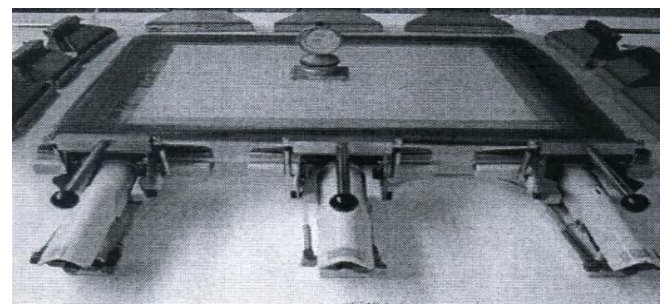

a)
2 - 90.40 ULTRA ORANGE - яркооранжевая ткань, плотность - 90 нит/см, диаметр нити - 40 мкм, размер отверстия открытой части ячейки - 69 мкм, коэффициент открытой поверхности - $38.5 \%$, толщина ткани - 68 мкм, теоретический объем краски $-26 \mathrm{~cm} / \mathrm{m}^{2}$, вес -32 $\Gamma / \mathrm{M}^{2}$.

Контроль натяжения ткани выполняется при помощи тензометра [4].

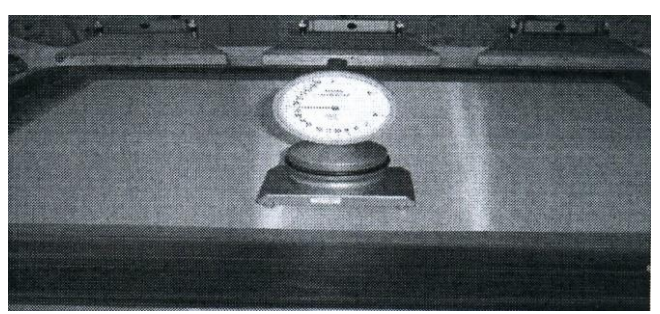

б)

Рисунок 2 - Контроль натяжения ткани при помощи тензометра: а - размещение и показание тензометра в центре рамы; б - размещение и показание тензометра на расстоянии 150 мм от края рамы по периметру в четырех точках.

Приклеивание ткани к раме выполняют двухкомпонентным клеем марки KIWOBOND 1000 НМТ [5] и сенсибилизатором-отвердителем марки KIWODYR 1000 HMT в соотношении частей компонентов 5:1.

KIWOBOND 1000 HMT - клей красного цвета, обеспечивающий устойчивое к химикатам сцепление сетки с рамами из любых материалов. Применяется для высокомодульных сеток, обладающих высокой степенью натяжения. Обладает хорошей устойчивостью к растворителям, после отверждения не становится хрупким.

KIWODYR 1000 HMT имеет высокие адгезивные свойства и повышенную стойкость к агрессивным средам.
Компоненты использовать в течение $45-70$ минут после тщательного перемешивания.

После нанесения слоя сушку клея выполнять в течение 10 - 15 минут при температуре $18-25$ ${ }^{\circ} \mathrm{C}$.

Обезжиривание трафаретной ткани производится специальным составом PREGAN A9 в проявочной машине. PREGAN A9 биорегенерируемая вязкая жидкость препятствующая возникновению мелких отверстий и повреждений поверхности при нанесении фотоэмульсии прямым способом. Применяется для очистки, обезжиривания и химического шерохования сеток всех видов.

Остатки воды с ткани удаляются водоотсосом сверху вниз. 


\begin{tabular}{l|lrl|l|ll} 
& ISRA (India) & $=\mathbf{1 . 3 4 4}$ & SIS (USA) & $=\mathbf{0 . 9 1 2}$ & ICV (Poland) & $=\mathbf{6 . 6 3 0}$ \\
Impact Factor: & ISI (Dubai, UAE) $=\mathbf{0 . 8 2 9}$ & PUHU (Russia) $=\mathbf{0 . 2 3 4}$ & PIF (India) & $=\mathbf{1 . 9 4 0}$ \\
& GIF (Australia) & $\mathbf{0 . 5 6 4}$ & ESJI (KZ) & $=\mathbf{1 . 0 4 2}$ & IBI (India) & $\mathbf{4 . 2 6 0}$
\end{tabular}

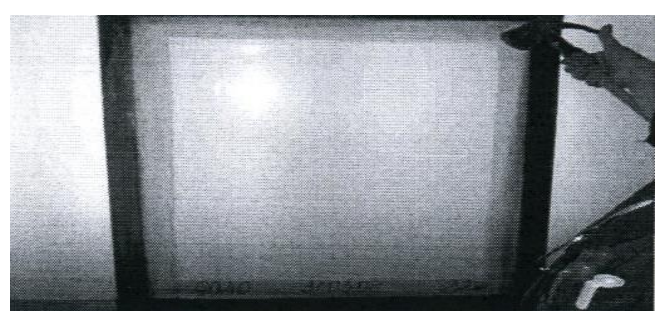

Рисунок 3 - Удаление остатков воды с ткани.

Сушка трафаретной рамы осуществляется в специальном сушильном шкафу модели HS. Процесс сушки должен длиться $1-1.5$ часа при температуре $40{ }^{\circ} \mathrm{C}$. Последующей операцией технологического процесса является нанесение фотоэмульсии на высушенную трафаретную раму. Для этого в специальный лоток заливают фотоэмульсию.

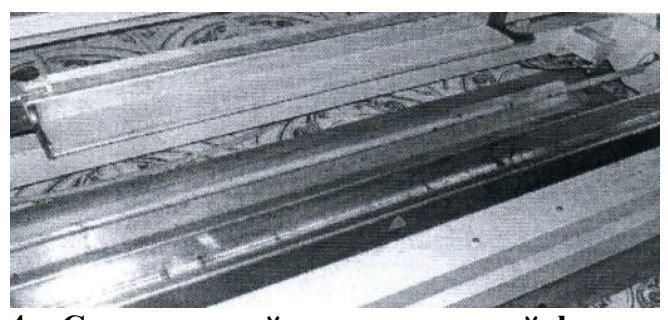

Рисунок 4 - Специальный лоток с залитой фотоэмульсией.

Нанесение фотоэмульсии осуществляется на специальной установке модели KIWOMAT 120/160. Нанесение фотоэмульсии выполняется в автоматическом режиме. Возможно нанесение фотоэмульсии на трафаретную раму по выбранной программе:

1. Для шкал. Шесть слоев фотоэмульсии с противоположной стороны рабочей поверхности ракеля [6].
2. Для фильтров. Один слой фотоэмульсии с рабочей стороны и два слоя фотоэмульсии с противоположной стороны рабочей поверхности ракеля.

Поверхность ракель-кюветы должна быть без повреждений. Закругленная кромка, наносящая фотоэмульсию, должна иметь выпуклость по всей длине.

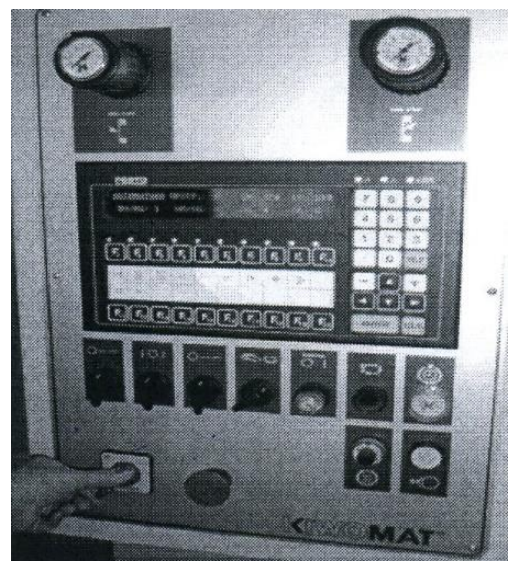

Рисунок 5 - Пульт управления установки для нанесения фотоэмульсии модели КІWОМАТ 120/160.

После 15 минут сушки трафаретной формы в сушильном шкафу при температуре $40{ }^{\circ} \mathrm{C}$ выполняют операцию экспонирования [7] на установке модели SIRI-ROP-SUPER 3. Для этого располагают фотошаблон на стекле копировальной рамы эмульсионным слоем вверх. На фотошаблон фотоэмульсионным слоем накладывается трафаретная рама. Для полного отсоса воздуха из копировальной рамы необходимо уложить в нее медную полосу с проушиной. К копировальной раме прижимают резиновое полотно. Производят поворот копировальной рамы на 90 градусов. По номеру программы выполняется экспонирование. Проявить рисунок путем промывки изображения (с двух сторон струей воды) в проявочной машине.

ISPC Generalization of scientific results, 


\begin{tabular}{l|lrl|l|ll} 
& ISRA (India) & $=\mathbf{1 . 3 4 4}$ & SIS (USA) & $=\mathbf{0 . 9 1 2}$ & ICV (Poland) & $=\mathbf{6 . 6 3 0}$ \\
Impact Factor: & ISI (Dubai, UAE) $=\mathbf{0 . 8 2 9}$ & PUHU (Russia) $=\mathbf{0 . 2 3 4}$ & PIF (India) & $=\mathbf{1 . 9 4 0}$ \\
& GIF (Australia) & $\mathbf{0 . 5 6 4}$ & ESJI (KZ) & $=\mathbf{1 . 0 4 2}$ & IBI (India) & $\mathbf{4 . 2 6 0}$
\end{tabular}

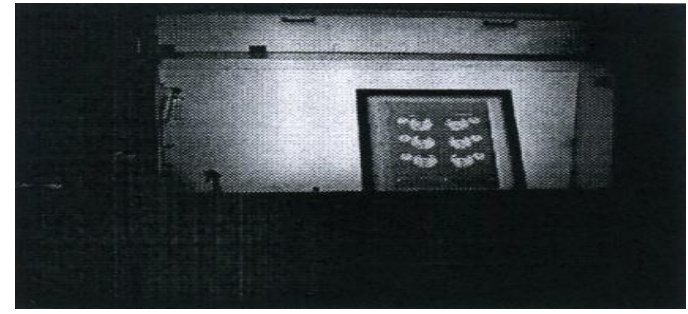

Рисунок 6 - Проявление изображения в проявочной машине.

Трафаретную форму сушить 30 минут в сушильном шкафу при температуре $40{ }^{\circ} \mathrm{C}$.

Годность трафарета определяется на монтажном столе с подсветкой (рис. 7).

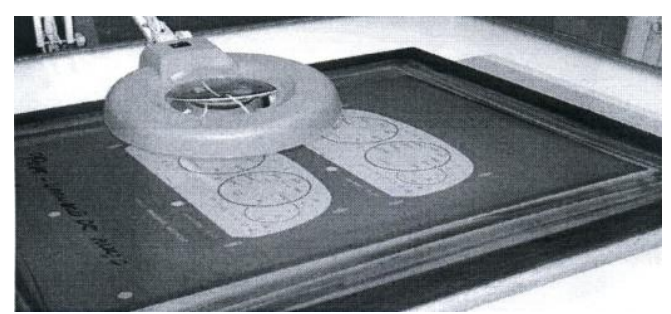

Рисунок 7 - Контроль качества изготовления трафарета на монтажном столе.

Годные к работе трафареты должны храниться в специальном шкафу. Перед установкой в модуль трафаретной печати THIEME 4020 [8] трафарет тщательно протирают салфеткой, смоченной в спирте. После окончания печати снимаются излишки печатной краски с трафарета. Остатки краски с трафарета смываются щеткой, из которой вытекает растворитель. Трафарет протереть салфеткой, смоченной в спирте.

Если при визуальном осмотре в ячейках ткани не обнаружено остатков краски, трафарет считается годным к работе. После сушки трафарет ставится в шкаф.

Общий вид готовых трафаретов после окончательной сушки представлен на рис. 8.

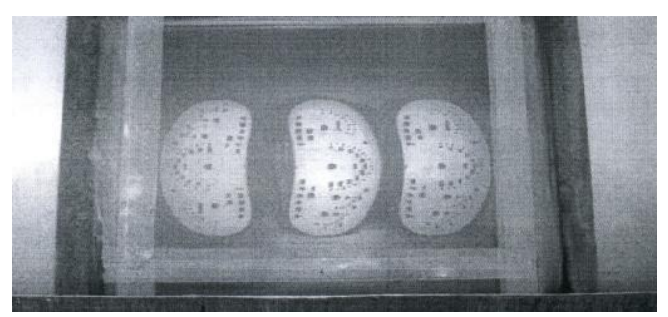

Рисунок 8 - Трафареты после окончательной сушки.

Трафарет считается годным, если он не порвался, фотоэмульсионный слой держится и не смывается, отсутствуют механические повреждения. Тиражеустойчивость данных трафаретов не оговаривается, и они могут использоваться неопределенное время.

\section{Заключение}

Нанесение различных по сложности изображений на материал при помощи трафаретной печатной формы является наиболее оптимальным методом изготовления шкал приборной панели автомобилей. Применение моноволоконной полиэфирной ткани в качестве обрабатываемого материала и специальное высокоточное технологическое оборудование позволяет получить трафаретную форму с высокими эксплуатационными свойствами.

Авторы выражают благодарность Андроповой Л.М. за предоставленные фотографии. 


\begin{tabular}{l|lrl|l|ll} 
& ISRA (India) & $=\mathbf{1 . 3 4 4}$ & SIS (USA) & $=\mathbf{0 . 9 1 2}$ & ICV (Poland) & $=\mathbf{6 . 6 3 0}$ \\
Impact Factor: & ISI (Dubai, UAE) $=\mathbf{0 . 8 2 9}$ & PUHIL (Russia) $=\mathbf{0 . 2 3 4}$ & PIF (India) & $=\mathbf{1 . 9 4 0}$ \\
& GIF (Australia) & $\mathbf{0 . 5 6 4}$ & ESJI (KZ) & $=\mathbf{1 . 0 4 2}$ & IBI (India) & $\mathbf{= 4 . 2 6 0}$ \\
& JIF & $\mathbf{1 . 5 0 0}$ & SJIF (Morocco) & $=\mathbf{2 . 0 3 1}$ & & \\
\hline
\end{tabular}

\section{References:}

1. (2016) Poliefiry.

Available:

https://ru.wikipedia.org/wiki/Полиэфиры (Accessed: 20.12.2016).

2. (2016) Fotoemulsiya. Available: https://ru.wikipedia.org/wiki/Фотоэмульсия (Accessed: 20.12.2016).

3. (2016) Setka dlya trafaretnoy pechati. Available:

http://www.euroscreen.ru/index.php?option=co $\underline{\mathrm{m}}$ content $\&$ view $=$ article $\& \mathrm{id}=61$ : screennet $\& \mathrm{cat}$ $\mathrm{id}=40$ : screenbook \&Itemid $=73 \quad$ (Accessed: 20.12.2016).

(Accessed:

4. (2016) Mehanicheskie i elektricheskie tenzometry. http://www.devicesearch.ru/article/8523

(Accessed: 20.12.2016).

5. (2016) Kley dlya trafaretnyh setok Kiwobond 1000 HMT. Available: http://www.spmachine.ru/kiwobond_1000.htm (Accessed: 20.12.2016).

6. (2016) Rakel. Available: https://ru.wikipedia.org/wiki/Ракель (Accessed: 20.12.2016).

7. (2016) Eksponirovanie. Available: https://traditio.wiki/Экспонирование (Accessed: 20.12.2016).

8. (2016) Machinery examples. Available: http://www.thieme.eu/en/machinery_examples (Accessed: 20.12.2016). 